\title{
Comparing patient and endoscopist perceptions of the colonoscopy indication
}

\author{
Maida J Sewitch $\mathrm{PhD}^{1,2}$, Dara Stein $\mathrm{MSc}^{2}$, Lawrence Joseph $\mathrm{PhD}^{2,3}$, Alain Bitton MD FRCPC ${ }^{1,4}$, \\ Robert J Hilsden MD PhD FRCPC ${ }^{5}$, Linda Rabeneck MD MPH FRCPC ${ }^{6}$, Lawrence Paszat BA MD MS FRCPC 7,8 , \\ Jill Tinmouth MD PhD ${ }^{9}$, Mary Anne Cooper MD MEd ${ }^{10}$
}

MJ Sewitch, D Stein, L Joseph, et al. Comparing patient and endoscopist perceptions of the colonoscopy indication. Can J Gastroenterol 2010;24(11):656-660.

BACKGROUND: Determining whether a colonoscopy is performed for screening or nonscreening purposes can facilitate clinical practice and research. However, there is no simple method to determine the colonoscopy indication using patient medical files or health administrative databases.

OBJECTIVE: To determine patient-endoscopist agreement on the colonoscopy indication.

METHODS: A cross-sectional study was conducted among staff endoscopists and their patients at seven university-affiliated hospitals in Montreal, Quebec. The study participants were 50 to 75 years of age, they were able to understand English or French, and were about to undergo colonoscopy. Self- (endoscopist) and interviewer-administered (patient) questionnaires ascertained information that permitted classification of the colonoscopy indication. Patient colonoscopy indication was defined as the following: perceived screening (routine screening, family history, age); perceived nonscreening (follow-up); medical history that implied nonscreening; and a combination of the three preceding indications. Agreement between patient and endoscopist indications was measured using concordance and Kappa statistic.

RESULTS: In total, 702 patients and 38 endoscopists participated. The three most common reasons for undergoing colonoscopy were routine screening/regular check-up (33.8\%), follow-up to a previous problem $(30.2 \%)$ and other problem $(24.6 \%)$. Concordance (range 0.79 to 0.85 ) and Kappa (range 0.58 to 0.70 ) were highest for perceived nonscreening colonoscopy. Recent large bowel symptoms accounted for 120 occurrences of disagreement in which the patient perceived a nonscreening colonoscopy while the endoscopist perceived a screening colonoscopy.

CONCLUSIONS: Patient self-report may be an acceptable means for rapidly assessing whether a colonoscopy is performed for screening or nonscreening purposes. Delivery of patient-centred care may help patients and endoscopists reach a shared understanding of the reason for colonoscopy.

Key Words: Accuracy; Colonoscopy; Indication; Screening

Oolonoscopy is as central to any colorectal cancer (CRC) screening strategy as either the initial screening examination or the follow-up to a positive examination by fecal occult blood test (FOBT), flexible sigmoidoscopy or double-contrast barium enema $(1,2)$. Determining whether a colonoscopy is

\section{Comparer la perception des patients et des endoscopistes quant à l'indication de coloscopie}

HISTORIQUE : Le fait de déterminer si une coloscopie est effectuée pour des besoins de dépistage ou non peut faciliter la pratique clinique et la recherche. Cependant, il n'existe pas de méthode simple pour déterminer l'indication de coloscopie au moyen du dossier médical du patient ou des bases de données administratives en santé.

OBJECTIF : Déterminer l'entente entre le patient et l'endoscopiste quant à l'indication de coloscopie.

MÉTHODOLOGIE : Les chercheurs ont mené une étude transversale auprès des endoscopistes et de leurs patients dans sept hôpitaux universitaires de Montréal, au Québec. Les participants à l'étude avaient de 50 à 75 ans, comprenaient l'anglais ou le français et étaient sur le point de subir une coloscopie. Un questionnaire autoadministré (endoscopistes) ou administré par un intervieweur (patients) a permis de vérifier l'information pour classer l'indication de coloscopie. L'indication de coloscopie des patients était définie comme suit : perception de dépistage (dépistage habituel, antécédents familiaux, âge), perception d'absence de dépistage (suivi), antécédents médicaux qui sous-tendaient l'absence de dépistage et une combinaison des trois indications précédentes. L'entente entre les indications du patient et celles de l'endoscopiste était mesurée selon la concordance et les statistiques de Kappa.

RÉSULTATS : Au total, 702 patients et 38 endoscopistes ont participé. Les trois principales raisons de subir une coloscopie étaient un dépistage habituel ou une vérification régulière $(33,8 \%)$, le suivi d'un problème connu $(30,2 \%)$ et un autre problème $(24,6 \%)$. La concordance (plage de 0,79 à 0,85 ) et l'analyse statistique Kappa (plage de 0,58 à 0,70 ) étaient plus élevées pour une coloscopie perçue comme ne servant pas au dépistage. Des symptômes récents du gros intestin ont donné lieu à 120 occurrences de mésentente selon lesquelles le patient croyait qu'il ne subissait pas une coloscopie de dépistage, tandis que l'endoscopiste percevait le contraire.

CONCLUSIONS : Le rapport des patients peut constituer un moyen acceptable d'évaluer rapidement si une coloscopie est effectuée pour des besoins de dépistage ou non. La prestation de soins axés sur le patient peut aider les patients et les endoscopistes à avoir la même perception de la raison d'effectuer la coloscopie.

performed for screening or nonscreening purposes may facilitate epidemiological and clinical research such as documenting trends in CRC screening and evaluating the effectiveness of CRC screening improvement strategies (3). Presently, however, there is no simple method to determine the indication for

${ }^{1}$ Department of Medicine, McGill University; ${ }^{2}$ Division of Clinical Epidemiology, The Research Institute of the McGill University Health Centre;

${ }^{3}$ Department of Epidemiology and Biostatistics, McGill University; ${ }^{4}$ Division of Gastroenterology, McGill University Health Centre, Montreal,

Quebec; ${ }^{5}$ Departments of Medicine/Community Health Sciences, University of Calgary, Calgary, Alberta; ${ }^{6}$ Department of Medicine,

University of Toronto, Toronto; ${ }^{7}$ Radiation Oncology Research Unit, Department of Oncology, Queen's University; ${ }^{8}$ Kingston Regional Cancer

Centre, Department of Community Health and Epidemiology, Queen's University, Kingston; ${ }^{9}$ Division of Gastroenterology; ${ }^{10}$ Sunnybrook

Health Sciences Centre, University of Toronto, Toronto, Ontario

Correspondence: Dr Maida J Sewitch, 687 Pine Avenue West, V-Building, The Royal Victoria Hospital, Montreal, Quebec H3A 1A1.

Telephone 514-934-1934 ext 44736, fax 514-934-8293, e-mail maida.sewitch@mcgill.ca

Received for publication November 5, 2009. Accepted February 15, 2010 
colonoscopy from either health administrative databases (4-6) or patient medical files $(3,7,8)$. Patient self-report could be used to obtain this information, although the degree to which patients and their endoscopists agree on the indication for colonoscopy is unclear. In one small Canadian study (9), 76\% of patients and their primary care physicians matched on the reason for undergoing CRC screening by any modality. Thus, the purpose of the present study was to examine the utility of patient self-report of the colonoscopy indication by determining the agreement between patients and endoscopists regarding the indication for colonoscopy. Having an easy and acceptable means to identify the colonoscopy indication would facilitate clinical research and optimize the utility of health administrative data. Moreover, understanding the nature of disagreement between patients and endoscopists may help to promote the delivery of more effective patient care.

\section{METHODS}

\section{Study design and sites}

The present cross-sectional study was conducted among staff endoscopists and their patients at seven university-affiliated hospitals in Montreal, Quebec (January to March 2007). The study was part of a larger prospective study aimed at developing a classification system for categorizing the colonoscopy indication. Study sites included the Montreal General Hospital, the Royal Victoria Hospital, The Sir Mortimer B Davis Jewish General Hospital, St Mary's Hospital Center, L'Hotel Dieu, Hôpital Maisonneuve-Rosemont and Hôpital Fleury.

\section{Data collection among endoscopists}

Staff endoscopists who performed colonoscopy at the study sites were recruited before patient enrollment. Immediately after performing the index colonoscopy for each participating patient, the endoscopist completed a postcolonoscopy questionnaire that had been attached to the outside of the patient's medical file by the research assistant. The postcolonoscopy questionnaire contained one item that prompted the endoscopist to indicate the reason for performing the colonoscopy from among the following reasons - screening: the individual was asymptomatic and at average-risk for developing CRC or had a family history of CRC; surveillance: the individual had a history of either colon polyps, CRC, ulcerative colitis or Crohn's disease; diagnostic: the individual had large bowel symptoms; confirmatory: the individual required follow-up to a positive screen to confirm or rule out disease; and the individual had another problem (open-ended question).

\section{Data collection among patients}

A convenience sample of patients was recruited in the endoscopy waiting room immediately before the performance of the index colonoscopy. Eligible patients were 50 to 75 years of age, able to understand English or French and scheduled to undergo a colonoscopy with a participating endoscopist. Patients who lacked coverage under the provincial health insurance plan in the previous year or were unable to give consent (eg, severe dementia) were excluded. A research assistant administered the patient questionnaire immediately before the colonoscopy. Data regarding age, sex, education and CRC family history (first-degree relative) were collected. Medical history was considered to be gastrointestinal (GI) history (inflammatory bowel disease [ulcerative colitis or Crohn's disease]), colon polyps, CRC, colon/bowel surgery, positive FOBT in the previous 12 months) and large bowel symptoms in the previous six months (rectal bleeding on more than one occasion, unintentional weight loss of more than $4.5 \mathrm{~kg}$, marked change in bowel habits, lower abdominal/rectal pain and anemia). One item assessed the patient's perception of the reason(s) for undergoing the index colonoscopy (routine screening/regular check-up, family history of CRC, age, follow-up to previous problem, follow-up to previous screening test, other, and do not know or recall).

Ethics approval was obtained from the McGill University Faculty of Medicine Institutional Review Board (Montreal, Quebec) and the research ethics boards of the participating institutions before study inception. The endoscopists and patients provided written informed consent before participation.

\section{Endoscopist and patient definitions of the colonoscopy indication}

Endoscopist colonoscopy indication was considered to be screening if the endoscopist checked screening on the questionnaire, and was considered to be nonscreening if the endoscopist checked surveillance, diagnostic, confirmatory or other.

Patient colonoscopy indication was defined in four ways. Indications 1 and 2 were derived from the patient questionnaire item on the reason for having the colonoscopy. For indication 1 , the colonoscopy was considered to be screening if the patient checked either regular check-up/routine screening, age or family history of CRC. For indication 2, the colonoscopy was considered to be nonscreening if the patient checked follow-up to either a previous screening test or to a previous problem, or there was another problem (eg, colon polyps). In contrast to indications 1 and 2, indication 3 was derived from the questionnaire items on medical history (GI history and large bowel symptoms in the previous six months). For indication 3, the colonoscopy was considered to be nonscreening if the patient checked either GI history or large bowel symptoms in the previous six months. Indication 4 combined indications 1, 2 and 3 such that the colonoscopy was considered to be screening only if the patient checked routine screening, family history of colorectal cancer or age, and did not check follow-up to previous screening test, previous problem, other problem, gastrointestinal history or large bowel symptoms.

\section{Statistical analysis}

Descriptive statistics were used to characterize the patient sample. Agreement between patient and endoscopist perceptions of the colonoscopy indication was measured by concordance and the Kappa statistic (10). Concordance was calculated as the proportion of patients and endoscopists who agreed that the colonoscopy indication was for screening or nonscreening divided by the total number of patients in the study. Kappa is a measure of agreement that accounts for agreement that occurs by chance alone. SAS version 9.1 (SAS Institute Inc, USA) was used for all analyses. Given the small sample size, the results were not stratified according to endoscopist nor was a random effects model built according to endoscopist. However, there was no evidence of large differences between endoscopists when the raw data were reviewed. 
TABLE 1

\section{Patient characteristics}

\begin{tabular}{lc}
\hline Characteristic & $\%$ \\
\hline Age, years (mean \pm SD) & $61 \pm 6.9$ \\
Female & 49.4 \\
Education & \\
High school or less & 23.0 \\
High school graduate & 15.4 \\
Attended/graduated college/CEGEP/technical school & 19.1 \\
Attended/graduated university & 42.5 \\
Gastrointestinal history & 29.2 \\
Inflammatory bowel disease* & 3.4 \\
Colorectal cancer & 4.4 \\
Colon/bowel surgery & 7.7 \\
Colon polyps & 23.4 \\
Family history of colorectal cancer (first-degree relative ${ }^{\dagger}$ ) & 22.1 \\
Positive FOBT in previous 12 months & 2.3 \\
Large bowel symptoms in the previous six months & 46.9 \\
Rectal bleeding & 21.7 \\
Unintentional weight loss & 2.7 \\
Change in bowel habits & 17.4 \\
Lower abdominal/rectal pain & 15.4 \\
Anemia & 11.5 \\
\hline
\end{tabular}

*Ulcerative colitis or Crohn's disease; ${ }^{\dagger}$ Parent, child or sibling. CEGEP Postsecondary education collegiate institution; FOBT Fecal occult blood test

\section{RESULTS}

Thirty-eight staff endoscopists (35 gastroenterologists, two surgeons and one internist) participated in the study. Of the 770 eligible patients approached to participate, 53 (6.8\%) refused. Of the 717 remaining patients, two patients $(0.3 \%)$ withdrew after enrollment and 13 patients (1.8\%) were excluded for other reasons (incorrect questionnaire used [n=3], missing data $[\mathrm{n}=6]$ and nonperformance of the colonoscopy $[\mathrm{n}=4])$. Thus, 702 patients $(91.2 \%)$ were included in the present study.

\section{Patients}

Table 1 shows that the mean age of patients was 61 years, $50.6 \%$ were men and $42.5 \%$ attended or graduated from university. GI history showed that $29.2 \%$ of the patients had either colon polyps, colon/bowel surgery, CRC, inflammatory bowel disease or a positive FOBT in the previous 12 months. Large bowel symptoms in the previous six months were
TABLE 2

Patient perception of the reason for colonoscopy

\begin{tabular}{lcc}
\hline Reason & $\mathbf{n}$ & \% (95\% Cl) \\
\hline Routine screening/regular check-up & 237 & $33.8(30.1-37.1)$ \\
Age & 118 & $16.8(14.0-19.5)$ \\
Family history of colorectal cancer & 115 & $16.4(13.6-19.0)$ \\
Follow-up to previous problem & 212 & $30.2(26.6-33.4)$ \\
Follow-up to a previous screening test & 17 & $2.4(1.3-3.5)$ \\
Other problem* & 173 & $24.6(21.3-27.7)$ \\
\hline
\end{tabular}

Percentages may not sum to $100 \%$ because patients could check more than one item. *Previous colon polyps

reported by $46.9 \%$ of patients. Table 2 presents the distribution of patient responses for the reason for undergoing colonoscopy. The three most common reasons were routine screening/ regular check-up (33.8\%), follow-up to a previous problem (30.2\%) and other problem (24.6\%).

\section{Agreement}

To illustrate how the measures of agreement were derived, Figure 1 presents the $2 \times 2$ tables for the four patient colonoscopy indications compared with the endoscopist colonoscopy indication. Table 3 presents the agreement measures for the data presented in Figure 1. Concordance ranged from 0.79 to 0.85 and Kappa ranged from 0.58 to 0.70 ; both measures of agreement were highest for indication 2. Indication 4 resulted in the highest number of occurrences in which the patient indicated nonscreening while the endoscopist indicated screening $(\mathrm{n}=120)$. Table 4 shows that GI history accounted for $20.8 \%$ of these occurrences while recent large bowel symptoms accounted for $81.7 \%$.

\section{DISCUSSION}

Patient self-report of a nonscreening reason for colonoscopy showed satisfactory measures of patient-endoscopist agreement, providing support for its use as a means for rapidly assessing whether a colonoscopy is performed for screening or nonscreening purposes. Questioning patients as to why they are undergoing a colonoscopy may easily be accomplished in the endoscopy unit, with the response recorded in the patient's medical file. This information is potentially useful for research as well as for practice delivery purposes, especially in situations of disagreement due to ambiguities regarding the true reason

\section{Patient indication $1^{*}$}

\begin{tabular}{|l|l|c|c|}
\hline \multicolumn{2}{|c|}{} & \multicolumn{2}{|c|}{ Endoscopist } \\
\cline { 3 - 4 } \multicolumn{2}{|c|}{} & Screening & Nonscreening \\
\hline \multirow{2}{*}{ Patient } & Screening & 312 & 79 \\
\cline { 2 - 4 } & Nonscreening & 38 & 273 \\
\hline
\end{tabular}

${ }^{*}$ Routine screening, family history of colorectal cancer, age

\section{Patient indication 2*}

\begin{tabular}{|l|l|c|c|}
\hline \multicolumn{2}{|c|}{} & \multicolumn{2}{|c|}{ Endoscopist } \\
\cline { 3 - 4 } \multicolumn{2}{|c|}{} & Screening & Nonscreening \\
\hline \multirow{2}{*}{ Patient } & Screening & 287 & 42 \\
\cline { 2 - 4 } & Nonscreening & 63 & 310 \\
\hline
\end{tabular}

*Follow-up to previous screening test or previous problem, or another problem

\begin{tabular}{|c|c|c|c|}
\hline & & \multicolumn{2}{|c|}{ Endoscopist } \\
\hline & & Screening & Nonscreening \\
\hline \multirow{2}{*}{ Patient } & Screening & 239 & 36 \\
\hline & Nonscreening & 111 & 316 \\
\hline
\end{tabular}

*Medical history (gastrointestinal history and large bowel symptoms)

Patient indication $4^{*}$

\begin{tabular}{|l|l|c|c|}
\hline \multicolumn{2}{|c|}{} & \multicolumn{2}{c|}{ Endoscopist } \\
\cline { 3 - 4 } \multicolumn{2}{|c|}{} & Screening & Nonscreening \\
\hline \multirow{2}{*}{ Patient } & Screening & 230 & 21 \\
\cline { 2 - 4 } & Nonscreening & 120 & 331 \\
\hline
\end{tabular}

${ }^{*}$ Combination of indications 1, 2 and 3

Figure 1) $2 \times 2$ tables illustrating patient and endoscopist perceptions of the colonoscopy indication according to the four patient colonoscopy indications. Data presented as $n$ 
TABLE 3

Agreement estimates and $95 \%$ Cls for the four measures of the patient indication for colonoscopy

\begin{tabular}{lcccc}
\hline & \multicolumn{4}{c}{ Patient colonoscopy indication } \\
\cline { 2 - 5 } & $\mathbf{1 *}^{\mathbf{*}}$ & $\mathbf{2}^{\dagger}$ & $\mathbf{3}^{\ddagger}$ & $\mathbf{4}^{\S}$ \\
\hline Concordance & 0.83 & 0.85 & 0.79 & 0.80 \\
Kappa (95\% Cl) & 0.67 & 0.70 & 0.58 & 0.60 \\
& $(0.61-0.72)$ & $(0.65-0.75)$ & $(0.52-0.64)$ & $(0.54-0.65)$ \\
\hline
\end{tabular}

${ }^{*}$ Routine screening, family history of colorectal cancer and age; ${ }^{\dagger}$ Follow-up to previous screening test or previous problem or another problem; ${ }^{\ddagger}$ Medical history (gastrointestinal history and large bowel symptoms); ${ }^{\S}$ Combination of indications 1, 2 and 3

for the procedure. In fact, based on patient indication 4 , the majority of disagreement occurred when patients believed that the colonoscopy was for nonscreening purposes while the endoscopists believed it was for screening, similar to the results reported by Gordon et al (11); therefore, either the physician was in error or the patient had a serious misperception about his/her health. While symptom information may have been lacking in the endoscopy referral form, recent large bowel symptoms may have developed during the colonoscopy wait period, which averages 71 days (interquartile range 33 to 149 days) in Quebec (12). Therefore, when the endoscopist and the patient disagree on the colonoscopy indication, she or he may intervene by providing patient-centred care, probing the patient for recent changes in medical history in an attempt to dispel misconceptions the patient may have about personal health or, when necessary, to correct his or her own misperceptions of the patient's health. Such communication may in itself be therapeutic for the patient, and lead to reduced anxiety, increased satisfaction with care and, eventually, better adherence to future CRC screening $(13,14)$.

One strength of our study was the novel methodology whereby questionnaires were completed by patients and endoscopists at the time of colonoscopy, thereby reducing the possibility of endoscopist recall bias. We also compared four classifications of the patient colonoscopy indication to find the one that yielded optimal agreement. Our findings suggest that most patients understand the circumstances for undergoing a colonoscopy; in fact, only 62 patients $(8.8 \%)$ endorsed reasons that would indicate both a screening and nonscreening procedure (data not shown).

Our findings also need to be interpreted in light of the study limitations. The present study was conducted at university-affiliated hospitals in Montreal in which the majority of patients $(62 \%)$ had completed postsecondary education; therefore, the results may not be generalizable to nonuniversityaffiliated hospitals outside of Montreal. To reduce the potential for recall bias introduced by the patient questionnaire items on medical history, we limited the time frame to the past 12 months for FOBT testing and the past six months for large bowel symptoms.

\section{CONCLUSION}

The present study of endoscopists and their patients who underwent colonoscopy found that patient self-report was a satisfactory means to rapidly assess the colonoscopy indication. Asking patients whether the colonoscopy was for follow-up to a positive screening test, or to a previous or other problem,

\section{TABLE 4}

Medical history of patients who indicated nonscreening while the endoscopist indicated screening, according to indication $4^{*}(n=120)$

\begin{tabular}{lc}
\hline Characteristic & $\%(95 \% \mathrm{Cl})$ \\
\hline Gastrointestinal history & $20.8(13.5-28.2)$ \\
Colon polyps & $14.2(7.5-19.7)$ \\
Colorectal cancer & 0 \\
Colon/bowel surgery & $6.7(2.0-10.8)$ \\
Inflammatory bowel disease $^{\dagger}$ & 0 \\
Positive FOBT in the previous 12 months & $0.8(0.6-3.8)$ \\
Large bowel symptoms in the previous 6 months $_{\text {Rectal bleeding }}$ & $81.7(74.6-88.7)$ \\
Unintentional weight loss & $36.1(26.2-43.2)$ \\
Change in bowel habit & $1.7(0.6-3.8)$ \\
Lower abdominal/rectal pain & $24.2(15.7-30.7)$ \\
Anemia & $23.3(15.0-29.8)$ \\
\hline
\end{tabular}

*Indication 4: Combination of indication 1 (routine screening, family history of colorectal cancer, age), indication 2 (follow-up to previous screening test or previous problem or another problem) and indication 3 (medical history [gastrointestinal history and large bowel symptoms]); Percentages may not sum to $100 \%$ because more than one item could have been endorsed. 'Ulcerative colitis or Crohn's disease. FOBT Fecal occult blood test

yielded more and better measures of patient-endoscopist agreement compared with asking whether the colonoscopy was for screening, age, family history of CRC or for medical history. This method of assessing the colonoscopy indication could be easily implemented in the endoscopy unit, and may be used for both clinical and research purposes. Because the true reason for patient-endoscopist disagreement is unclear, further exploration of the patient's medical history by the endoscopist may lead to a shared understanding and an enhanced therapeutic relationship that, ultimately, increase the likelihood for patient adherence to future CRC screening.

FUNDING: This research was funded by the National Cancer Institute of Canada through an operating grant awarded to Maida Sewitch. Maida J Sewitch is supported as a Research Scientist of the Canadian Cancer Society through an award from the National Cancer Institute of Canada. Lawrence Joseph is a Chercheur Nationaux of the Medical Research Council of Quebec (Fonds de la recherche en santé du Québec).

\section{REFERENCES}

1. Winawer SJ. Colorectal cancer screening. Best Pract Res Clin Gastroenterol 2007;21:1031-48.

2. Lieberman DA, Faigel DO, Logan JR, et al. Assessment of the quality of colonoscopy reports: Results from a multicenter consortium. Gastrointest Endosc 2009;69(Suppl 3):645-53.

3. Pignone M, Scott TL, Schild LA, Lewis C, Vasquez R, Glanz K. Yield of claims data and surveys for determining colon cancer screening among health plan members. Cancer Epidemiol Biomarkers Prev 2009;18:726-31.

4. Freeman JL, Klabunde CN, Schussler N, Warren JL, Virnig BA, Cooper GS. Measuring breast, colorectal, and prostate cancer screening with medicare claims data. Med Care 2002;40(Suppl 8):IV-36-IV-42.

5. Haque R, Chiu V, Mehta KR, Geiger AM. An automated data algorithm to distinguish screening and diagnostic colorectal cancer endoscopy exams. J Natl Cancer Inst Monographs 2005;35:116-8. 
6. Schenck AP, Klabunde CN, Warren JL, et al. Data sources for measuring colorectal endoscopy use among Medicare enrollees. Cancer Epidemiol Biomarkers Prev 2007;16:2118-27.

7. Fisher DA, Voils CI, Coffman CJ, et al. Validation of a questionnaire to assess self-reported colorectal cancer screening status using face-to-face administration. Dig Dis Sci 2009;54:1297-306

8. Ferrante JM, Ohman-Strickland P, Hahn KA, et al. Self-report versus medical records for assessing cancer-preventive services delivery. Cancer Epidemiol Biomarkers Prev 2008;17:2987-94.

9. Khoja S, McGregor SE, Hilsden RJ. Validation of self-reported history of colorectal cancer screening. Can Fam Physician 2007;53:1192-7.

10. Cohen J. A coefficient of agreement for nominal scales. Educ Psychol Meas 1960;20:37-46.
11. Gordon NP, Hiatt RA, Lampert DI. Concordance of self-reported data and medical record audit for six cancer screening procedures. J Natl Cancer Inst 1993;85:566-70.

12. Armstrong D, Barkun AG, Chen Y, et al. Access to specialist gastroenterology care in Canada: The Practice Audit in Gastroenterology (PAGE) wait times program. Can J Gastroenterol 2008;22:155-60.

13. Street RL Jr, Makoul G, Arora MK, Epstein RM. How does communication heal? Pathways linking clinician-patient communication to health outcomes. Patient Educ Couns 2009;74:295-301.

14. Collins DL, Street RL Jr. A dialogue model of conversations about risk: Coordinating perceptions and achieving quality decisions in cancer care. Soc Sci Med 2009;68:1506-12. 


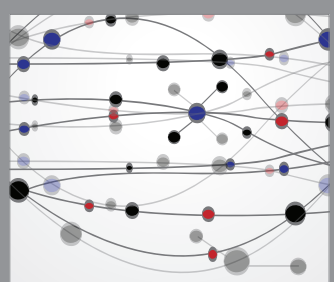

The Scientific World Journal
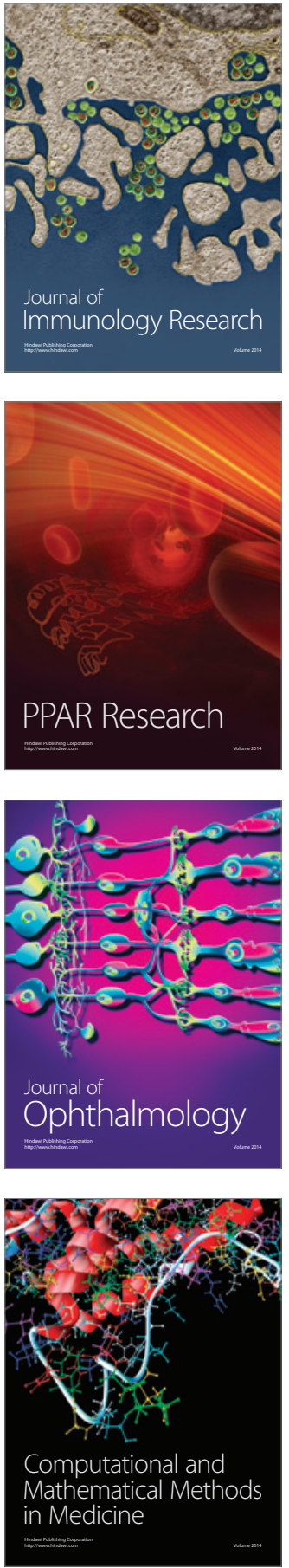

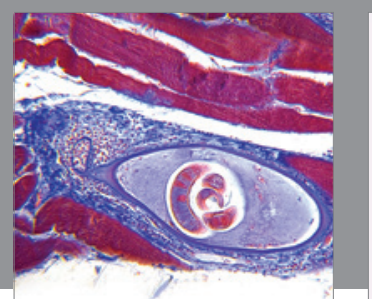

Gastroenterology Research and Practice

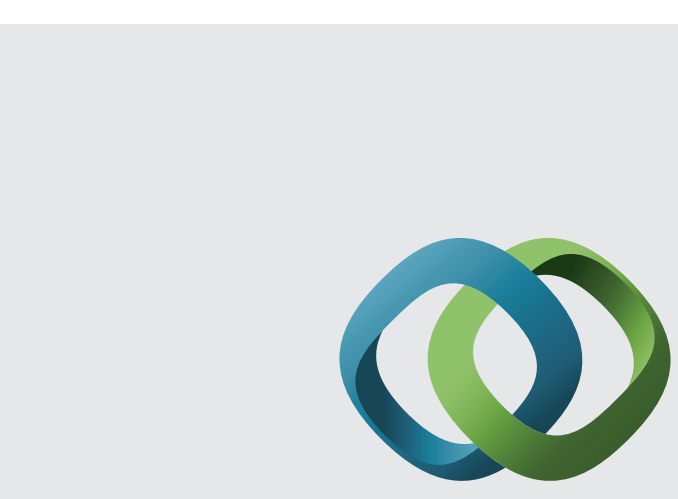

\section{Hindawi}

Submit your manuscripts at

http://www.hindawi.com
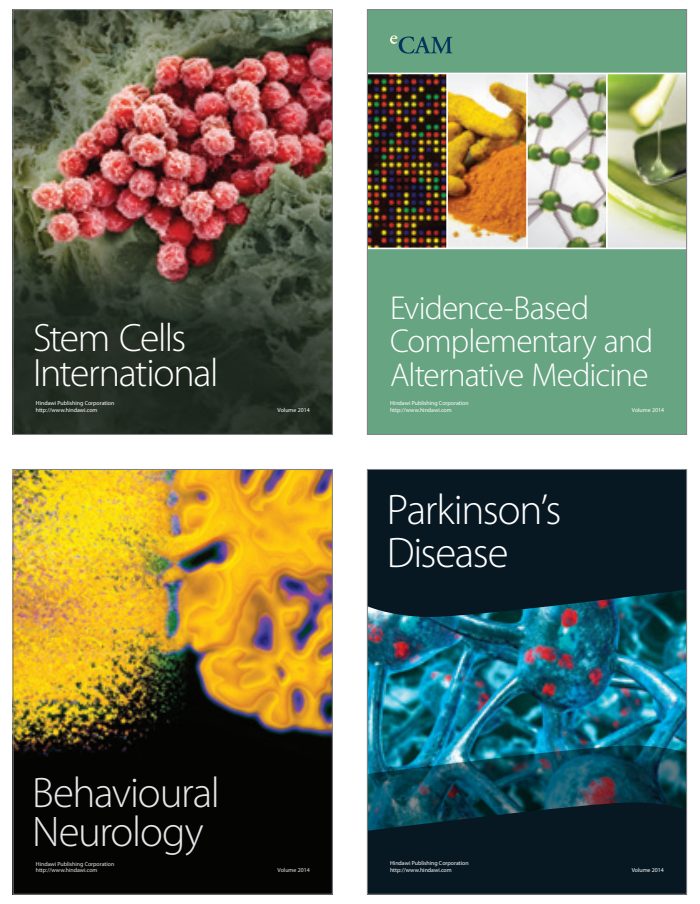
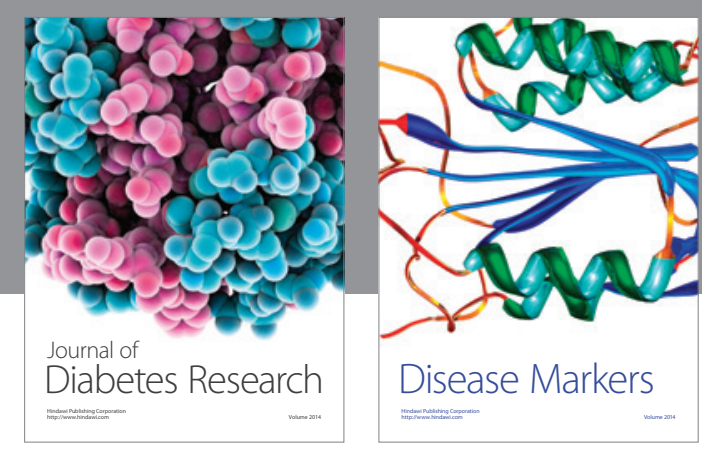

Disease Markers
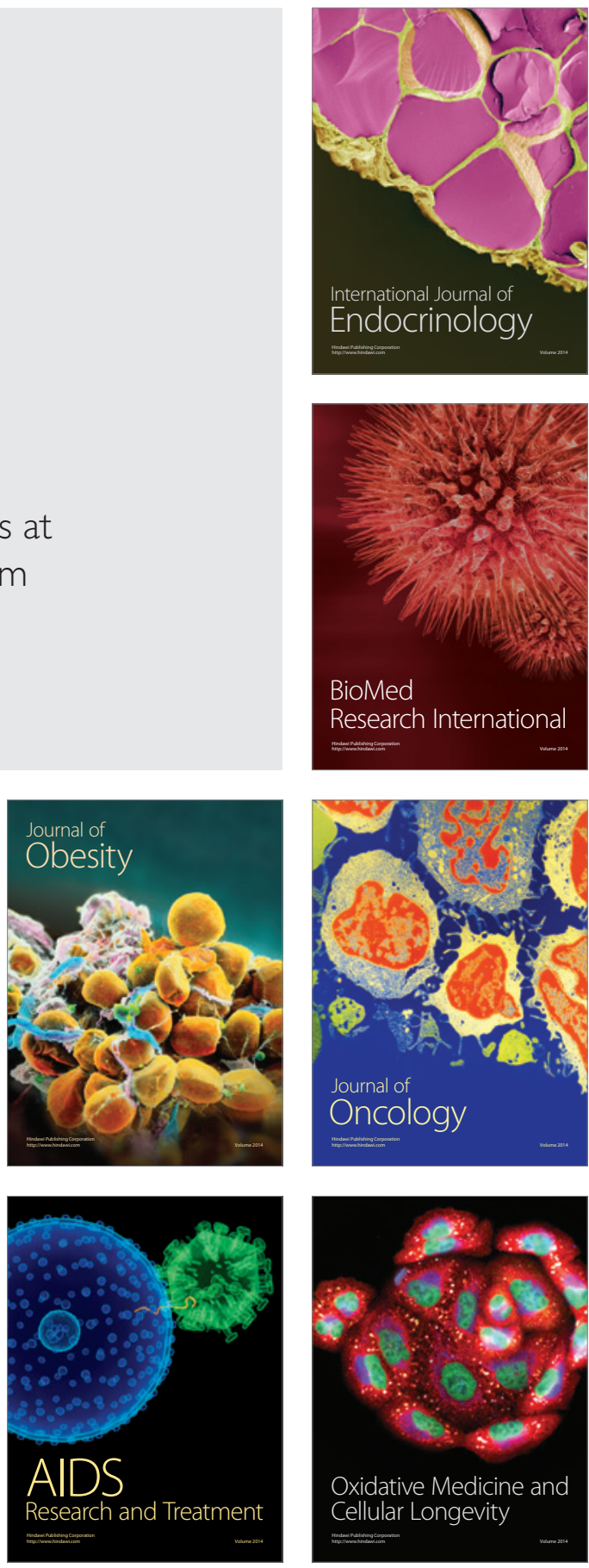